\title{
Aves sin nido, de Clorinda Matto de Turner: um romance peruano nos limiares da tradução cultural
}

Roseli Barros Cunha

Resumo: Neste artigo, o objetivo é tratar do romance Aves sin nido (1889) da autora peruana Clorinda Matto de Turner e de sua primeira tradução para a língua portuguesa do Brasil, ainda inédita. Abordo, seguindo a teoria de Genette ([1987] 2009), especificamente, elementos paratextuais presentes no romance. A localização de alguns peritextos na obra, nos quais são traduzidos termos e expressões da cultura quéchua e da região serrana peruana para a língua castelhana, são indícios de que a autora procurava construir um caminho de leitura para seu público. Ainda que se possa questionar a eficácia no romance em questão, tal procedimento representou, sem dúvida, uma etapa importante dentro da bistória da literatura peruana. Anos mais tarde, a proposta foi repensada e recriada por José María Arguedas ao longo de sua trajetória literária e denominada por Sales (2002) como "tradução cultural".

Palavras-chave: tradução, paratextos, tradução cultural, literatura peruana, literatura feminina.

Em Tinta escreveu Clorinda Matto de Turner seu romance Aves sin nido, primeira tentativa de romance peruano, a primeira descrição que se faz da vida miserável do índio peruano. (ARGUEDAS, [1940] 2012, p. 288, tradução minha) $)^{1}$.

(...) aquilo por meio de que um texto se torna livro e se propõe como tal a seus leitores, e de maneira mais geral ao público. Mais do que um limite ou uma fronteira estanque, trata-se aqui de um limiar, ou - expressão de Borges ao falar de um prefácio - de um "vestíbulo", que oferece a cada um a possibilidade de entrar, ou de retroceder. (GÉNETTE ([1987] 2009, p. 9).

1 En Tinta escribió Clorinda Matto de Turner su novela Aves sin nido, primer intento de novela peruana, la primera descripción que se hace de la vida miserable del indio peruano. 


\section{Introdução}

A partir do que Gérard Genette expõe na obra Paratextos editoriais ([1987] 2009) em relação ao que denomina genericamente "prefácio", percebo que Clorinda Matto de Turner, no romance Aves sin nido (1889), dispõe de forma bastante peculiar de dois peritextos. Além da presença desses elementos, a localização deles demonstra que procurava realizar algo mais do que introduzir na obra palavras e expressões da língua quéchua e do castelhano peculiar da região serrana do Peru. Ainda que de modo embrionário, denotava estar procurando uma forma de traduzir elementos da cultura quéchua e serrana para a criolla peruana daquela época, ao realizar, conforme as palavras de José María Arguedas, lidas na epígrafe, "uma primeira tentativa de romance peruano" (ARGUEDAS, [1940] 2012, p. 288). Esse procedimento representa apenas um "preâmbulo" em toda a busca que Arguedas empreenderá ao longo de sua trajetória literária e culminará em um processo denominado por Sales (2002) tradução cultural, conforme se tem discutido (CUNHA, 2015).

A nossos olhos, na atualidade, o procedimento adotado por Matto de Turner pode parecer rudimentar e ineficiente como tentativa de tradução e, mais ainda, de uma tradução cultural. Entretanto, sem dúvida, representaria um dos vários movimentos de aproximação realizados por intelectuais peruanos, na época, em relação a questões atinentes à região serrana do Peru. Seriam reivindicações ainda embrionárias, mas empreendidas pouco depois por grupos indigenistas e medidas governamentais (ESCAJADILLO, [1980] 2004; VALCÁRCEL, 2013). $\mathrm{Na}$ literatura, especificamente, alguns autores procuraram dar visibilidade aos problemas enfrentados pelas comunidades indígenas e mestiças da serra peruana e a elementos representativos dessas culturas. Deste modo, é importante evidenciar a aproximação que Matto de Turner propõe de temas pulsantes para os leitores que lhe eram contemporâneos por meio de paratextos e de traduções. Por isso, na primeira tradução do romance para a língua portuguesa do Brasil, ainda inédita, tais paratextos foram mantidos conforme a concepção da autora. Isso colaborará para que o leitor entenda o contexto de produção da obra e seu lugar dentro da história literária não apenas do Peru, mas da América Latina.

\section{Clorinda Matto de Turner e sua obra: pioneirismo e polêmicas}

Clorinda Matto de Turner (1852-1909), escritora, jornalista, educadora e também tradutora do castelhano para o quéchua (MATTO DE TURNER, 1994, 
p. 169-171), teve sua obra marcada pelo pioneirismo e por controvérsias. Para Vargas Yábar (2013, p. 19), inclusive, a autora foi polêmica em vida e continua sendo um século depois de sua morte. Se as reflexões e reivindicações que fez sobre a situação de desigualdade e exploração em que viviam as mulheres e os indígenas, principalmente na região da serra peruana no século XIX, parecem brandas aos olhos da contemporaneidade; naquela época, porém, a atitude e a obra da autora representaram um grande passo para uma maior visibilidade e participação de ambos no processo de modernização da sociedade peruana do século XIX.

A fortuna crítica sobre a produção de Matto de Turner registra opiniões bastante distintas desde a publicação de seu primeiro romance até hoje, século XXI (CORNEJO POLAR [1992] 2005; FERREIRA, 2005; SALES, 2006; VARGAS YÁBAR, 2013). Algumas enfatizam na produção jornalística e literária da autora uma visão bastante convencional da mulher e de seu papel na sociedade, enquanto outros percebem um feminismo pioneiro possível para a época. Na concepção de Vargas Yábar (2013), Matto foi, ao longo dos anos, alvo de duras críticas porque sua atuação como romancista e intelectual incomodava, por ser ela uma mulher atuando dentro da ordem social hierárquica e patriarcal da sociedade e por ela assumir "o papel de guia político dos destinos da nação e do continente. E que essa mulher desempenhasse tal função, no século XIX, equivale a colocar o mundo de cabeça para baixo (...)"². (VARGAS YÁBAR, 2013, p. 22, tradução minha).

Diante disso, a conclusão de Velázquez Castro parece-me bastante ponderada. Para ele, não há ingenuidade na postura da autora; ela "é consciente dos recursos que tem e, baseado neles, constrói estratégias que lhe permitem ser escutada tanto por seu público quanto por setores reacionários”3 (VELÁZQUEZ CASTRO, 2013, p. 14). A importância de tal atitude pioneira ao tratar de temas tão polêmicos na época evidencia-se pelo fato de sua obra estar sendo revisitada por vários críticos contemporâneos. Esse, inclusive, é um dos motivos que atestam a validade de uma tradução de seu primeiro romance para a língua portuguesa do Brasil.

Clorinda Matto de Turner, nascida em Cusco, em 1852, no Peru, passou a infância na fazenda do pai, no povoado de Paullu Chico. Em 1871, mudou-se para Tinta, a 120 quilômetros de Cusco, onde começou a publicar poemas e ensaios em jornais andinos (MATTO DE TURNER, 1994, p. 169). Seu conterrâneo e leitor

2 (...) el papel de guía política de los destinos de la nación y del continente. Y que esa mujer desempeñe esa función, en el siglo XIX, equivale a poner el mundo al revés (...).

3 (...) es consciente de los recursos que posee y, en base a ellos, construye estrategias que le permiten ser escuchada tanto por su público como por sectores reaccionarios. 
José María Arguedas, ao afirmar que Matto escreveu Aves sin nido, publicado em 1889, em Tinta, povoado do qual ela saíra em 1884, valoriza a origem serrana e o conhecimento da cultura e língua indígenas da autora.

Em 1889, além de publicar o primeiro romance, tornou-se editora de um dos mais importantes jornais da época, El Perú Ilustrado. Mas em 1890 a Igreja Católica empreendeu uma campanha difamatória contra o periódico. Segundo alguns biógrafos (SALES, 2006, p. 39), por causa do escândalo em 1891, Matto foi obrigada a renunciar ao cargo de editora. No mesmo ano, publicou o segundo romance Índole. Em 1892, fundou e dirigiu a La equitativa, editora que empregava apenas mulheres e pela qual ela publicou a obra teatral Hima Súmac, outros trabalhos de sua própria autoria, o jornal político e literário Los Andes (1892-1893) e obras de outras escritoras.

Em 1894, com a chegada de Andrés Avelino Cáceres à presidência da República, Matto de Turner passou a apoiá-lo e a criticar seu oponente Nicolás de Piérola. Em 1895, mesmo ano em que publicou Herencia, Piérola tomou o governo em Lima e Cáceres foi exilado. Clorinda Matto, por ser partidária do ex-presidente, teve sua casa e a editora saqueadas (SALES, 2006, p. 40). Diante dos novos rumos políticos, resolveu exilar-se em 1895. Passou pelo Chile, mas se estabeleceu na Argentina, onde continuou atuante e deu início ao periódico Búcaro Americano (1896-1909). Nessa época, publicou no exterior, dedicou-se à docência e ainda traduziu os Evangelhos e textos de Novo Testamento para o quéchua.

Em 1908, passou vários meses na Europa; porém, com a saúde debilitada, retornou à Buenos Aires, onde faleceu em 1909. Seu último livro Viaje de recreo foi publicado postumamente. Em 1924, o presidente Augusto Leguía solicitou o translado dos restos mortais de Clorinda Matto ao Peru (MATTO DE TURNER, 1994, p. 171) reconhecendo, de certa forma, a importância da autora e de sua obra na história literária e cultural peruana.

\section{Elementos paratextuais: os prefácios}

Na Introdução de Paratextos editoriais ([1987] 2009), Gérard Genette afirma que uma obra literária, um texto, apresenta-se, geralmente, acompanhado de outras produções, sejam estas verbais ou não, que "o cercam e prolongam" no intuito de "apresentá-lo" (p. 9). Tais elementos são denominados por ele "paratextos", os quais define como: 
(...) um conjunto heteróclito de práticas e de discursos de todos os tipos e de todas as idades que agrupo sob esse termo, em nome de uma comunidade de interesse, ou convergências de efeitos, que me parece mais importante do que sua diversidade de aspecto. (GENETTE, 2009, p. 10).

Ainda segundo o teórico, os paratextos subdividem-se entre peritexto e epitexto. Neste momento, interessa-me tratar do primeiro, indicado por ele como categoria espacial, por ter, necessariamente, um lugar "que se pode situar em relação àquela do próprio texto: em torno do texto, no espaço do mesmo volume, como o título ou o prefácio, e, às vezes, inserido nos interstícios do texto, como os títulos de capítulo ou certas notas (...)" (GENETTTE, 2009, p. 12).

Em relação a um desses peritextos, o prefácio, indica uma extensa lista de parassinônimos - "introdução", "nota", "preâmbulo", "prelúdio", "proêmio" -, mas afirma haver nuanças entres eles, muitas vezes devido à presença de mais de um deles em relação a um texto (GENETTE, 2009, p. 145) ou de ordem conotativa (p. 146), quando da própria escolha do termo que denominará o segmento. Deste modo, na concepção do teórico, "exórdio", "preâmbulo" ou "proêmio" indicariam um tom mais rebuscado ou pedante, enquanto "introdução", "nota" ou "notícia" uma maior modéstia, sincera ou fingida.

Seguindo a classificação do autor, em Aves sin nido, temos um prefácio autoral original (GENETTE, 2009, pp. 155-156), ou seja, um peritexto redigido pela própria escritora peruana para a primeira edição do romance, paratexto o qual ela escolheu denominar "proêmio". Distintamente do que Genette observa em relação a esse sinônimo, não se pode afirmar que haja no texto de Matto de Turner traços de rebuscamento ou pedantismo, mas sim um tom explicativo da proposta e do tema desenvolvido ao longo da obra. Esse elemento paratextual sinaliza ao leitor que ele está diante de um romance que tratará de questões referentes não apenas à sociedade daquela época, mas às necessidades daquele lugar. Conforme se lê, em vez de meramente seguir os passos de outros romances - como os chamados "de costume" - que lhe serviram de modelo e poderiam, por especificidades de seus outros contextos de produção, ter um caráter meramente recreativo, em Aves sin nido o intuito é o de alertar, ensinar os leitores e, até mesmo, estimulá-los a corrigir mazelas de sua sociedade:

\section{Proêmio}

Se a história é o espelho onde as gerações que estão por vir contemplarão a imagem das gerações que se foram; o romance deve ser a fotografia que 
estereotipe os vícios e virtudes de um povo, com a consequente moral corretiva para aqueles e a admiração expressa em homenagens para estas. Por isso, essa é a importância do romance de costumes, que, em suas páginas, contém muitas vezes o segredo da reforma de alguns tipos, quando não sua extinção.

Nos países nos quais, como o nosso, a LITERATURA se encontra em seus princípios, o romance tem que exercer maior influência na condescendência dos costumes. E, portanto, quando se apresenta uma obra com tendências impulsionadas a regiões superiores em relação àquelas em que esse romance nasce e vive, cuja trama é puramente amorosa ou recreativa, pode-se implorar a atenção do público e, como estendendo-lhe a mão, entregar a literatura ao povo. (MATTO DE TURNER, [1889] 2006, p. 93, tradução minha)4.

Seguindo a terminologia de Genette (2009, p. 159), o "destinador" deixa claro que realiza um prefácio autoral. Neste caso, deve-se dizer a "destinadora", uma vez que Clorinda Mattos de Turner apresenta suas ideias e concepções sobre a época em que vivia deixando transparecer sua condição de autora. Com tal procedimento, evidencia a presença e atuação feminina não apenas como observadora, mas como participante ativa na sociedade e no meio literário peruano do século XIX:

Movida por esse carinho, observei durante quinze anos inúmeros episódios que, se acontecessem na Suíça, Provença ou Saboia, teriam seu cantor, seu romancista ou seu historiador para os imortalizar com a lira e a pluma; mas, em minha distante pátria, conseguem apenas o descolorido lápis de uma irmã.

(...) E mesmo que não tivesse sido por outra coisa além de simples comiseração, a autora destas páginas terá alcançado seu propósito - recordando que no país existem irmãos que sofrem explorados na noite da ignorância, martirizados nessas trevas que pedem luz - assinalando questões que não têm pouca importância para os progressos nacionais e fažendo ao mesmo

4 Proemio / Si la historia es el espejo donde las generaciones por venir han de contemplar la imagen de las generaciones que fueron; la novela tiene que ser la fotografía que estereotipe los vicios y las virtudes de un pueblo, con la consiguiente moraleja correctiva para aquéllos y el homenaje de admiración para éstas. /Es tal, por esto, la importancia de la novela de costumbres, que en sus hojas contiene muchas veces el secreto de la reforma de algunos tipos cuando no su extinción. /En los países en que, como el nuestro, la LITERATURA se halla en su cuna, tiene la novela que ejercer mayor influjo en la morigeración de las costumbres; y, por lo tanto, cuando se presenta una obra con tendencias levantadas a regiones superiores a aquéllas en que nace y vive la novela cuya trama es puramente amorosa o recreativa; bien puede implorar la atención de su público para que extendiéndole la mano la entregue al pueblo. 
tempo literatura peruana. (MATTO DE TURNER, [1889] 2006, p. 94, tradução minha) $)^{5}$.

Ao longo da explanação sobre o que percebe no cotidiano de seu país e o que distintamente almeja construir, Matto procura a empatia do leitor. O proêmio ganha um tom dialógico e quase confessional, ainda que lance perguntas que podemos considerar retóricas, já que serão ilustradas e discutidas ao longo do romance:

Quem sabe se depois de virar a última página deste livro se perceberá a importância de observar atentamente as autoridades tanto eclesiásticas quanto civis que venham a reger os destinos dos que vivem nos afastados povoados do interior do Peru?

Quem sabe a necessidade do matrimônio dos padres seja reconhecida como uma exigência social?

(...) Amo com amor de ternura a raça indígena, por isso mesmo observei de perto seus costumes, encantadores por sua simplicidade, e a abjeção a que submetem essa raça aqueles mandões das vilórias que, se variam de nome, não declinam sequer do epíteto de Tiranos. Não são outra coisa, em geral, os padres, governadores, caciques e alcaides. (MATTO DE TURNER, [1889] 2006, pp. 93-94, tradução minha) ${ }^{6}$.

A autora faz então um esforço para reter o leitor, como diz Genette (2009, p. 176), "por um processo tipicamente retórico de persuasão", ao valorizar o tema que será tratado ao longo do romance e deixando perceptível a importância e a "utilidade de sua consideração" (p. 177). Deste modo, o "Proêmio" deixa bem

5 Llevada por este cariño, he observado durante quince años multitud de episodios que, a realizarse en Suiza, la Provenza o la Saboya, tendrían su cantor, su novelista o su historiador que los inmortalizase con la lira o la pluma; pero que, en lo apartado de mi patria, apenas alcanzan el descolorido lápiz de una hermana. / (...) y aun cuando no fuese otra cosa que la simple conmiseración, la autora de estas páginas habrá conseguido su propósito, recordando que en el país existen hermanos que sufren, explotados en la noche de la ignorancia; martirizados en esas tinieblas que piden luz; señalando puntos de no escasa importancia para los progresos nacionales y baciendo, a la vez, literatura peruana.

6 ¿Quién sabe si después de doblar la última página de este libro se conocerá la importancia de observar atentamente el personal de las autoridades, así eclesiásticas como civiles, que vayan a regir los destinos de los que viven en las apartadas poblaciones del interior del Perú? /¿Quién sabe si se reconocerá la necesidad del matrimonio de los curas como una exigencia social? / (...) Amo con amor de ternura a la raza indígena, por lo mismo que he observado de cerca sus costumbres, encantadoras por su sencillez, y la abyección a que someten esa raza aquellos mandones de villorrio, que si varían de nombre no degeneran siquiera del epíteto de Tiranos. No otra cosa son, en lo general los curas, gobernadores, caciques y alcaldes. 
claro que se destina, em um primeiro momento, a seus conterrâneos e, mais ainda, àqueles que partilham sua classe social, sua visão de mundo e se propõem empreender a tarefa de realizar mudanças na sociedade peruana.

Particularmente interessante é observar a possibilidade de se "procurar nos inícios (e eventualmente nos fins) de texto essas declarações pelas quais o autor apresenta e às vezes comenta sua obra”. (GENETTE, 2009, p. 147). Portanto, o autor pode expor suas ideias tanto no início, em um prefácio (entre tantos outros termos), ou em um posfácio, ao final, de todo modo com igual função: “[a]ssim, o 'posfácio' será considerado uma variedade de prefácio, cujos traços específicos, incontestáveis, parecem-me menos importantes do que aqueles que ele tem em comum com o tipo geral.” (GENETTE, 2009, p. 145).

Ainda sobre o lugar desse peritexto, Genette (2009, p. 154) argumenta que algumas obras podem apresentar dois prefácios. Em Aves sin nido, além do "Proêmio", temos outro peritexto, a saber, "Palavras que devem ser conhecidas antes de ler este livro" (Palabras que deben conocerse antes de ler este libro). Assim, seria de se esperar que tal elemento paratextual tivesse lugar ao início do romance. Para além da tese de que alguns "prefácios" são dispostos em posição pós-liminar no intuito de parecerem mais modestos e discretos (GENETTE, 2009, p. 154), em relação a essa obra de Matto de Turner, creio que o motivo do referido elemento no final seja outro.

É possível verificar que esse paratexto ocupa as páginas finais do romance tanto na primeira publicação, pela Imprenta del Universo, de Lima, em 1889, quanto em duas renomadas reedições, a da Biblioteca Ayacucho, de 1994, e a edição crítica preparada por Dora Sales, de 2006. A editora explica:

A própria autora inclui, paradoxalmente, no final do romance, uma seção intitulada "Palavras que devem ser conhecidas antes de ler este livro". Nesta edição, mantém-se tal subdivisão em sua localização final original, tal qual foi preparada por Matto (...). (MATTO DE TURNER, [1889] 2006, p. 75, tradução minha) $)^{7}$.

O procedimento criado por Matto de Turner e preservado em reedições da obra segue o que Genette afirma ser um dos objetivos do prefácio, "garantir

7 La propia autora incluye, paradójicamente, al final de la novela, una sección titulada "Palabras que deben conocerse antes de leer el libro". En esta edición se mantiene ese apartado en su ubicación final original tal y como la preparó Matto (...). 
ao texto uma boa leitura" (p. 176) ou, conforme assinala em outro momento de seu texto,

[o]rientar a leitura, tentar conseguir uma boa leitura, não passa apenas por instruções diretas. Consiste igualmente, e talvez em primeiro lugar, em colocar o leitor - definitivamente suposto - de posse de informações que o autor julga necessárias a essa boa leitura. (GENETTE, 2009, p. 186).

No caso do romance de Matto, a orientação localiza-se no final do romance. Mas, acompanhando o raciocínio de Genette, alguns leitores ao tomarem um livro podem folheá-lo pois, inclusive, como observa o teórico, a partir de Walter Scott, as pessoas dificilmente leem um prefácio e muitas vezes começam a ler um livro pelo fim (GENETTE, 2009, p. 154). Pensando assim, o leitor de Aves sin nido, certamente se encontraria com um peritexto cujo título é um alerta e - por que não dizer? - um modo de aguçar sua curiosidade em relação ao que lhe será apresentado.

Mas acredito que Clorinda Matto possa ter tido outra motivação. No que denominou "Proêmio", expõe ao leitor suas propostas literária e extraliterária. Procura estabelecer, de certo modo, uma identificação social e ideológica com o leitor. No outro paratexto, mostra que mesmo esse leitor identificado com a proposta poderia não estar habituado ou não ter conhecimento suficiente de algumas palavras e expressões da língua quéchua ou de um espanhol quechuizado e, ainda, de expressões peculiares à região da serra peruana, local onde é ambientado o romance. Ao não inserir tal peritexto no início do romance, Matto estaria possibilitando certa liberdade ao leitor de decidir pela leitura prévia ou não. E, talvez, mais ainda, mostrando a importância desse conhecimento, que deveria ser prévio, embora perpassando a leitura do romance, pois, sem dúvida, ao longo da leitura o leitor recorreria a ele. E, por se apresentar no final da obra, uma vez mais, antes de fechar o livro, o leitor se deparará com ele.

A autora estaria indicando, mais do que um modo de leitura, a necessidade de, ao retratar a sociedade serrana do Peru, fazer com que o leitor, mesmo aquele proficiente em língua espanhola e peruano, percebesse particularidades da região serrana e transitasse pelas duas línguas e culturas lá presentes. E é preciso recordar que um dos questionamentos posteriores em relação à obra da autora é o fato de ela assinalar apenas a mestiçagem entre o branco e o índio, não se preocupando com outros grupos étnicos tais como afro-peruanos, chineses e amazônicos (VELÁQUEZ CASTRO, 2013, p. 15). De todo modo, naquele momento, o que Matto tentava era, digamos, "traduzir" o Peru serrano aos demais peruanos, 
embrionariamente, formulando uma proposta de aproximação entre as culturas criolla, indígena e mestiça tal como empreenderiam os intelectuais indigenistas.

Dora Sales (2002), ao tratar da obra de José María Arguedas, defende que, ao longo de sua produção, o autor teria tentado vários procedimentos de tradução, procurando recriar em sua literatura elementos da cultura indígena e mestiça presentes na sociedade peruana. A crítica sustenta sua argumentação a partir de um comentário do próprio autor:

(...) depois de muitos anos de batalha e procura, Arguedas assume que a solução formal para sua prática narrativa passa por fazer do castelhano "o molde exato", trabalhando com ele a partir do interior. (...) Esta nova iniciativa devém em tradução: "Eu, agora, depois de dezoito anos de esforço, estou tentando uma tradução castelhana dos diálogos dos índios". (ARGUEDAS, 1950, p. 16). (SALES, 2002, p. 3, tradução minha) ${ }^{8}$.

Nas palavras da crítica, Arguedas empreende em Los ríos profundos (1958) uma tradução cultural:

Neste romance Arguedas aparece como tradutor da sensibilidade quéchua a um outro mundo. Se sua solução inicial passava por modificar sintaticamente o espanhol para procurar reproduzir a cadência da língua quéchua, agora opta por procurar usar a língua castelhana para transmitir estruturas de pensamento andinas, buscando expressar a lógica interna da cultura indígena, ainda que para isso também tenha empregado palavras quéchuas e orações com a sintaxe próxima à língua ameríndia. (SALES, 2002, p. 4, tradução minha) $)^{9}$.

Logicamente, não defendo que Matto de Turner, em 1889, tenha realizado tal procedimento que Arguedas, anos mais tarde, procurou ao longo de toda sua trajetória literária, mesmo porque ambos manifestam concepções bastante distintas

8 (...) tras muchos años de batalla y búsqueda, Arguedas asume que la solución formal para su práctica narrativa pasa por hacer del castellano "el molde justo", trabajando con él desde dentro. (...). Esta nueva iniciativa deviene en traducción: "Yo, ahora, tras dieciocho años de esfuerzo, estoy intentando una traducción castellana de los diálogos de los indios" (Arguedas, 1950, p. 16).

9 En esta novela Arguedas aparece como el traductor de la sensibilidad quechua a un mundo otro. Si su solución inicial pasaba por modificar sintácticamente el español para tratar de reproducir la cadencia de la lengua quechua, ahora opta por tratar de emplear la lengua castellana para transmitir estructuras de pensamiento andinas, buscando expresar la lógica interna de la cultura indígena, aunque para ello también empleó palabras quechuas y oraciones con la sintaxis próxima a la lengua amerindia. 
no modo de entender e de se relacionar com a cultura e língua indígenas. O fato de a autora, segundo sua biografia, ser serrana e bilíngue, capaz mesmo de realizar traduções do castelhano para o quéchua, não significa que se sentisse pertencente àquela cultura e buscasse por meio de sua obra promover uma identificação tal qual era o propósito de Arguedas. Afinal, como defende Walter Mignolo (2000, p. 231), com quem Sales (2002) concorda, há uma diferença significativa entre o bilinguism e o bilanguaging, uma vez que o segundo "não é uma preocupação gramatical, mas política, na medida em que o foco do bilanguaging em si é corrigir a assimetria das línguas e denunciar a colonialidade do poder e do conhecimento". (SALES, 2002, p. 4, tradução minha) ${ }^{10}$.

Portanto, podemos dizer que ser um indivíduo bilíngue, como Matto de Turner, não é o mesmo que querer pertencer a uma comunidade e não significa, mesmo em nível utópico, desejar alterar a situação de opressão em vivem os falantes dessa língua, assim como almejou Arguedas. Mas, de certo modo, o procedimento talvez rudimentar de tradução empreendido por Matto pode ter dado alguma visibilidade àquelas língua e cultura e um dos passos em direção ao procedimento empreendido por Arguedas, denominado por Sales "tradução cultural".

\section{Traduzir texto e paratextos}

Deste modo, ao realizar a primeira tradução da obra Aves sin nido para a língua portuguesa do Brasil, meu intuito foi evidenciar aos leitores a proposta de Matto de Turner. Em minha concepção, a autora usou alguns paratextos de sua obra, "Proêmio" e "Palavras que devem ser conhecidas antes de ler este livro" como maneiras de preparar o leitor para a entrada na serra peruana do século XIX representada no romance. Tais elementos textuais constituiriam uma espécie de "preâmbulo" nos quais a tradução de palavras e expressões da língua e da cultura indígena e mestiça da serra peruana tem o intuito de apresentar e acompanhar o leitor de língua espanhola, inclusive aquele peruano, mas não serrano, ao longo de seu percurso pelo romance e mesmo depois da leitura. Aos olhos de hoje, tal procedimento parece-nos esquemático e rudimentar, embora tenha servido de modelo a ser transposto por autores posteriores.

Com a decisão de manter esses elementos paratextuais em minha tradução, principalmente a seção "Palavras que devem ser conhecidas antes de ler este

10 Bilanguaging is not a grammatical but a political concern as far as the focus of bilanguaging itself is redressing the asymmetry of languages and denouncing the coloniality of power and knowledge. 
livro", no final do romance, conforme concepção da autora, minha intenção foi a de não apenas apresentar aos leitores da língua portuguesa do Brasil expressões peculiares da serra peruana do século XIX, mas também deixar evidente a proposta de aproximação que está por detrás da decisão de Matto de Turner. Para aqueles que acompanham a cena literária latino-americana - e, mais especificamente, a peruana -, deixar perceptível o caminho que a proposta literária de José María Arguedas, denominada "tradução cultural" por Sales (2002), percorreu, desde os primórdios com um procedimento atualmente controvertido, mas pioneiro para a época, adotado em Aves sin nido.

\section{Referências bibliográficas}

ARGUEDAS, José María. José María Arguedas. Obra Completa. Tomo VI. Lima: Horizonte, 2012.

CORNEJO POLAR, Antonio. Clorinda Matto de Turner, novelista. Estudios sobre Ave sin nido, Índole y Herencia. Lima: CELACP, [1992] 2005.

CUNHA, Roseli Barros. Transculturação (narrativa) e tradução (cultural) na América Latina. In: PONTES, V. O.; CUNHA, R. B. (Organizadores). A tradução e suas interfaces: múltiplas perspectivas. Curitiba: Editora CRV, 2015, pp. 25-35.

ESCAJADILLO, Tomás. Ciro Alegría, José María Arguedas y el indigenismo de Mariátegui. In: ESCAJADILLO, Tomás. Mariátegui y la literatura peruana. Lima: Amaru, [1980] 2004, pp. 233-286.

FERREIRA, Rocío. Introducción, Estudio crítico y bibliografía a Clorinda Matto de Turner. In: CORNEJO POLAR, Antonio. Clorinda Matto de Turner, novelista. Estudios sobre Ave sin nido, Indole y Herencia. Lima: CELACP, 2005, pp. 83-127.

GENETTE, Gérard. Paratextos editoriais. Tradução de Álvaro Faleiros. São Paulo: Ateliê Editorial, [1987] 2009.

MATTO DE TURNER, Clorinda. Aves sin nido. Castelló de Plana: Publicacions de la Universitat Jaume I, [1889] 2006.

MATTO DE TURNER, Clorinda. Aves sin nido. Prólogo de Antonio Cornejo Polar. Notas de Efraín Kristal e Carlos García Bedoya. Cronologia e bibliografía de Efraín Kristal. Caracas: Biblioteca Ayacucho, 1994.

MIGNOLO. Walter. Local Histories/Global Designs. Coloniality, Subaltern Knowledges, and Border Thinking. Princeton/Nova Jersey: Princeton University Press, 2000.

SALES, Dora. Introducción a Aves sin nido. In: MATTO DE TURNER, Clorinda. Aves sin nido. Castelló de Plana: Publicacions de la Universitat Jaume I, 2006, pp. 17-71.

SALES, Dora. Traducción cultural en la narrativa de José María Arguedas: hervores en la encrucijada de lenguas y culturas. In: Actas del I Congreso Internacional de Traductores e In- 
térpretes/II Congreso Nacional de Traductores, Universidad Femenina del Sagrado Corazón y Universidad Ricardo Palma, 2002, pp. 1-12.

VALCÁRCEL, Luis E. Luis E. Valcárcel: del indigenismo cusqueño a la antropología peruana. Lima: Copé, 2013.

VARGAS YÁBAR, Miguel. Las empresas del pensamiento. Clorinda Matto de Turner (1852-1909). Lima: Grupo Pakarina, 2013.

VELÁZQUEZ CASTRO, Marcel. Prólogo. In: VARGAS YÁBAR, Miguel. Las empresas del pensamiento. Clorinda Matto de Turner (1852-1909). Lima: Grupo Pakarina, 2013, pp. 11-15. 